\title{
Assessment of detoxification of malathion by Pseudomonas isolates
}

\author{
Shagufta Andleeb ${ }^{1 *}$ and Javed lqbal Qazi ${ }^{2}$ \\ ${ }^{1}$ Department of Zoology, Division of Science and Technology, College Road, Township Campus \\ University of Education, Lahore, Pakistan. \\ ${ }^{2}$ Environmental Microbiology Laboratory, Department of Zoology, University of the Punjab, Lahore, Pakistan.
}

Accepted 17 February, 2014

\begin{abstract}
Malathion degrading bacteria were isolated from a soil sample. Growth of mono and co-cultured strains of Pseudomonas in media containing the organophosphate insecticide, malathion as sole source of carbon was employed to assess degradability of the bacteria. On the seventh day of inoculation, bacteria free culture fluids as well as un-inoculated fluids were analyzed by gas chromatography and mass spectrometry (GC-MS). Malathion was not detected in the cell free culture fluids, instead four degradation products namely phoratoxon sulfone, malaoxon, butanedioic acid and ethyl methyl-methyl phosphonate made their appearance in the cultivation culture. All of the three strains used in this study, appeared efficient in degrading the insecticide especially in co-culturing conditions. These bacteria are promising for detoxifying the insecticide contaminated soils.
\end{abstract}

Key words: Pseudomonas, detoxification, malathion.

\section{INTRODUCTION}

Malathion [diethyl 2-\{(dimethoxyphosphorothioyl) sulfanyl $\}$ butanedioate] is a ten carbon compound used widely in agriculture and in public health pest control programs (US EPA, 2013), while in US, it is the most com-monly used organophosphate insecticide (Bonner et al., 2007).

Following application, malathion may be detected on plant surfaces up to 9 weeks (Delmore and Applelhans, 1991), yet with low persistence (Extoxnet, 2000) and rapid degradation in soil (Howard, 1991; Brenner, 1992). It is readily metabolized into even more toxic malaoxon in human body following absorption or injestion. Long-term oral exposure of malaoxon in rats has been found to be 61 times more toxic than malathion (Edwards, 2006). Despite lack of reliable information on adverse health effects of malathion (ATSDR, 2008), it has been found to induce oxidative stress in erythrocytes and alteration of the cellular antioxidant defense system (Durak et al.,
2009). However, it is cleared from the body in three to five days (Maugh, 2010).

Bacteria capable of malathion degradation have been well documented by various workers (Shan et al., 2009; Hamouda et al., 2013). This paper reports degradability of Pseudomonas isolates from chronically insecticide influenced soil.

\section{MATERIALS AND METHODS}

Three strains of Pseudomonas were isolated from soil in the vicinity of an insecticide formulating unit on a selective medium. This medium contained commercial grade malathion (50\%) as sole source of carbon as well as $\mathrm{K}_{2} \mathrm{HPO}_{4}$ (dipotassium hydrogen phosphate), $\mathrm{MgSO}_{4}$ (magnesium sulfate), $\mathrm{NH}_{4} \mathrm{NO}_{3}$ (ammonium nitrate), $\mathrm{FeSO}_{4} .7 \mathrm{H}_{2} \mathrm{O}$ (hydrated ferrous sulfate), $\mathrm{CaCl}_{2}$ (calcium chloride), copper nitrate, $\mathrm{MnCl}_{2}$ (manganese chloride), 


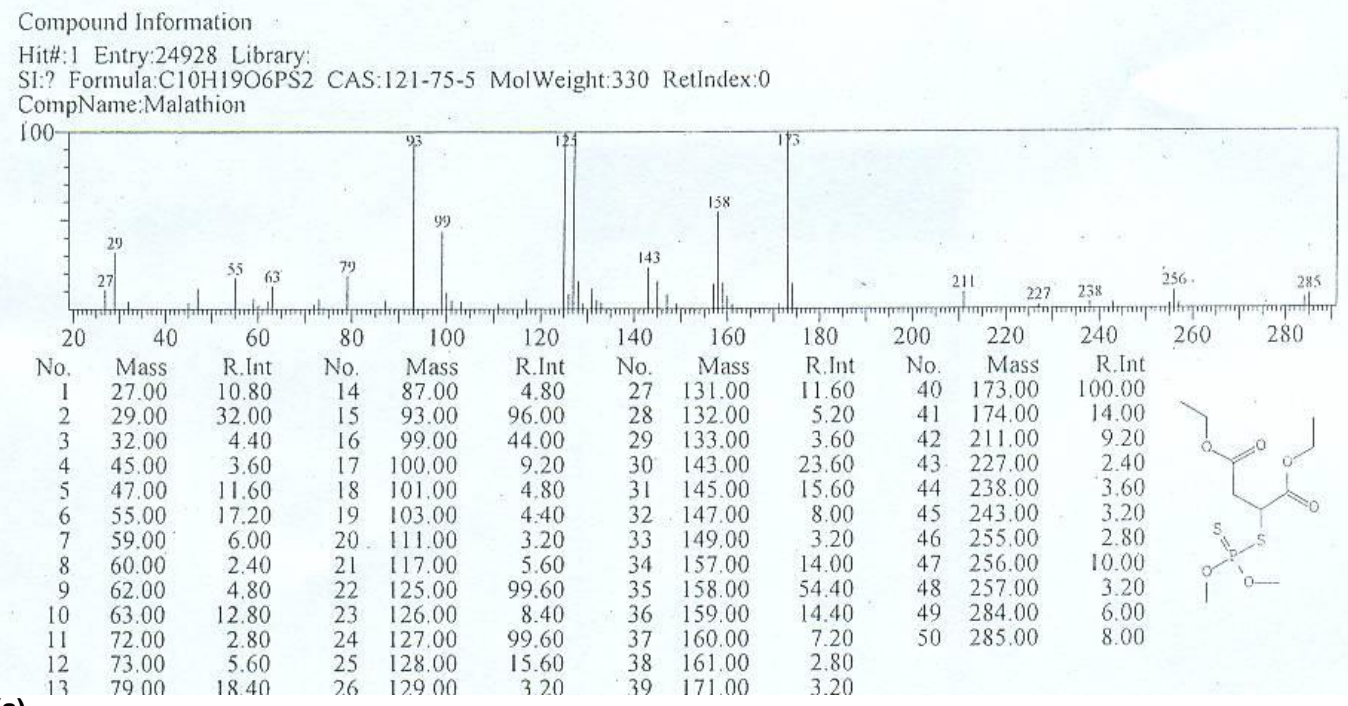

(a)

Compound Information

Hit\#:1 Entry:23816 Library:

SI:? Formula:C8H15O6PS2 CAS:1190-29-0 MolWeight:302 RetIndex:0

CompName:Butanedioic acid, [(dimethoxyphosphinothioyl)thio]-, 4-ethyl ester

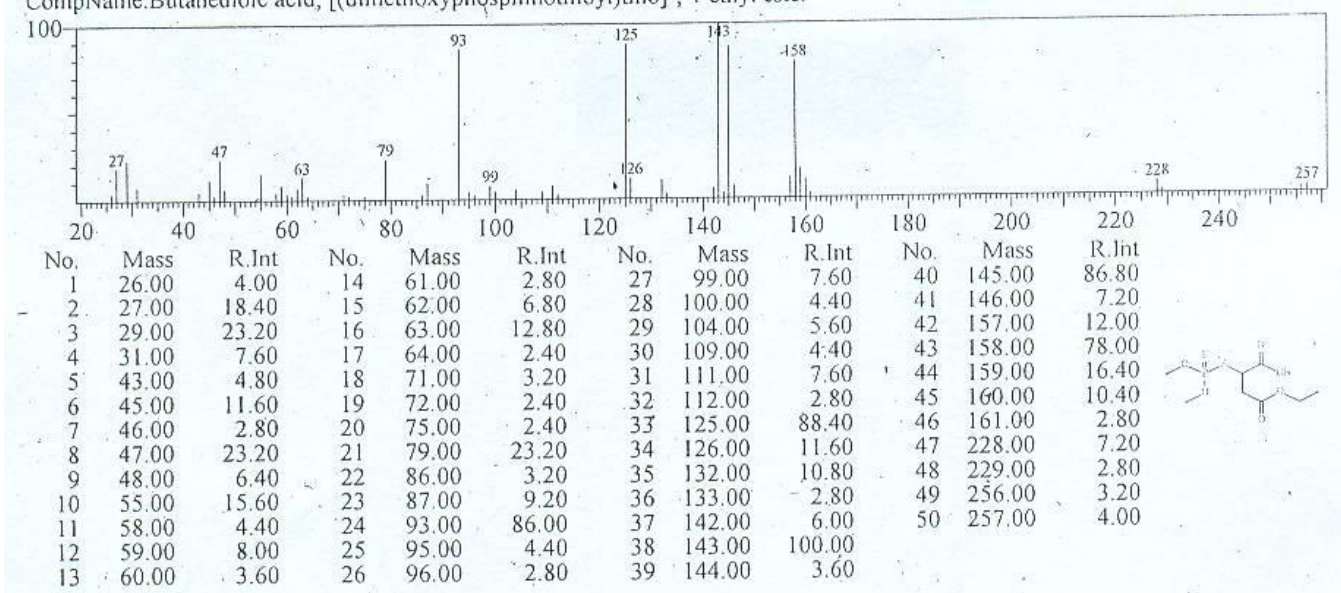

(b)

Figure 1. Chromatogram showing the presence of some molecules (a) Malathion (b) Butanedioic acid (c) Phoratoxon Sulfone and (d) Ethylmethyl methyl phosphonate.

zinc powder and agar (Andleeb et al., 2013). This medium was inoculated by mono and co-cultures of bacterial isolates at their optimum growth conditions with $5 \%$ inoculums size for Pseudomonas aeruginosa strain MY 06 and $10 \%$ inocula size for $P$. aeruginosa and $P$. aeruginosa strain SWD. Cultured fluids as well as un-inoculated control were sampled on seventh day of inoculation filtered through $0.2 \mu \mathrm{m}$ Millipore filters (Sartorius). The filters were analyzed by using technique GC-MS, available in HEJ (Hussain Ebrahim Jamal), Research Institute of Chemistry, University of Karachi. The column DB-5(optima-5) $30 \mathrm{~m} \times 0.25 \mathrm{~mm}$ was used with injection volume of $1.00 \mu \mathrm{l}$ and flow rate of 1.00 $\mathrm{ml} / \mathrm{min}$. Start temperature was $60^{\circ} \mathrm{C}$ for $5 \mathrm{~min}$ and end temperature was $280^{\circ} \mathrm{C}$ for $1 \mathrm{~min}$. Retention time was fixed at $15-35 \mathrm{~min}$ for detection of different compounds. An Agilent 6890 NGC was interfaced with a VG Analytical 79-250s double focusing mass spectrometer. MS operating conditions were ionization voltage 70 $\mathrm{eV}$ and ion source $250^{\circ} \mathrm{C}$. GC was fitted with a $30 \mathrm{~m} \times 0.32 \mathrm{~mm}$ fused capillary silica column coated with DB-5. Data were acquired by means of GC solution software (Shimadzu). Detection and identification of the insecticide and its metabolites produced as a result of bacterial metabolism was accomplished by consulting and comparing data with Standard Molecule library available at Department of Chemistry, Government College University, Lahore (Figure 1).

\section{RESULTS}

The GC/MS analysis detected the presence of malathion 
Compound Information

Hit:1 Entry:22475 Library:

SI:? Formula:C7H17O5PS2 CAS:2588-6-9 MolWeight:276 RetIndex:0

CompName:Phoratoxon sulfone

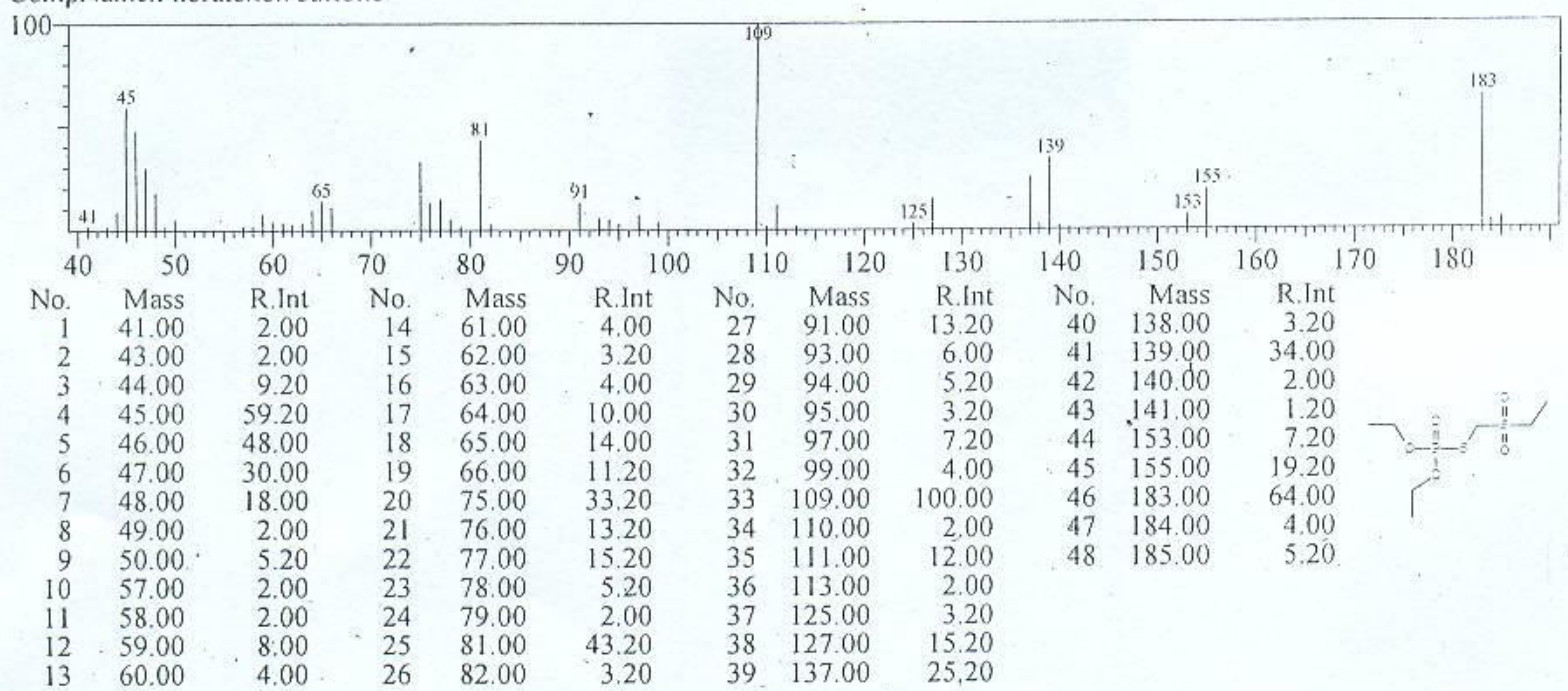

(c)

Compound Information

Hit\#:1 Entry:6478 Library:

SI:? Formula:C4H11O3P CAS:18755-36-7 MolWeight:138 Retlndex:0

CompName:Ethyl methyl methylphosphonate

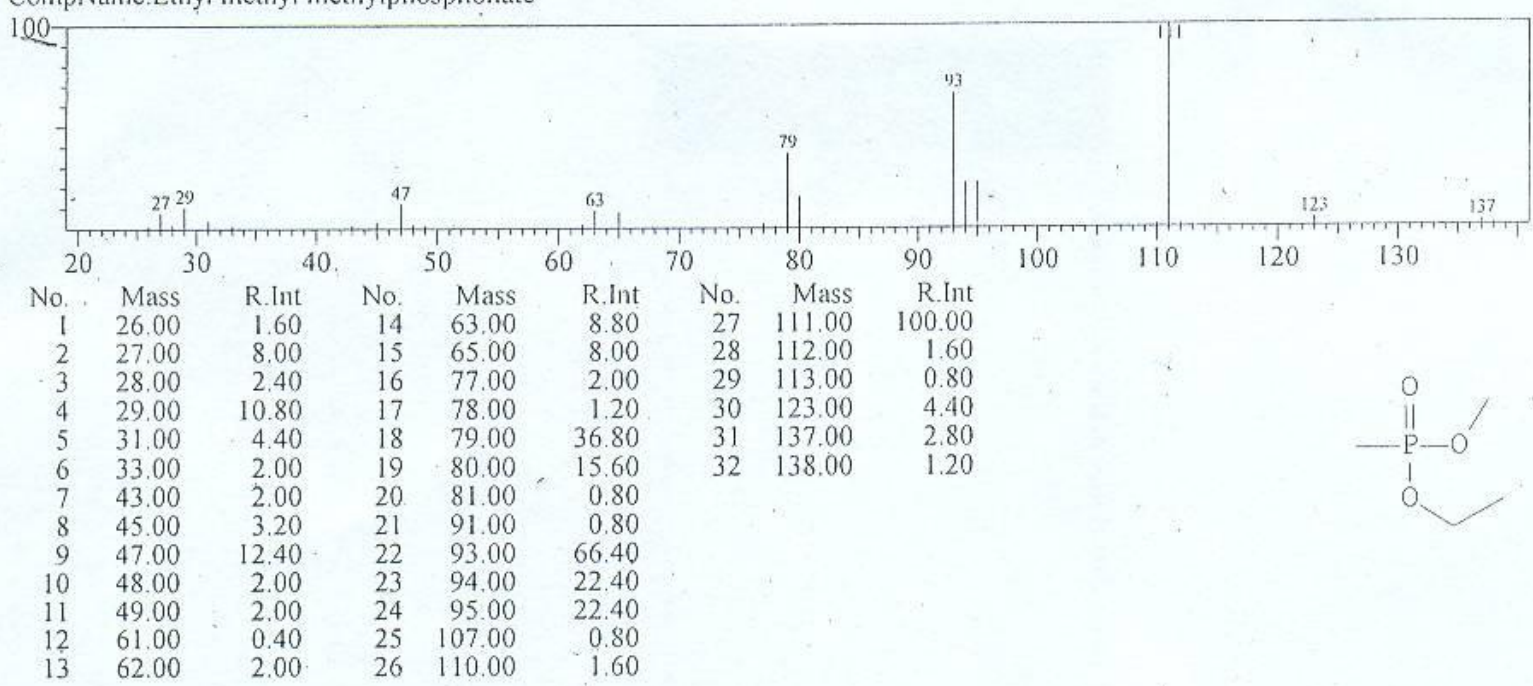

(d)

Figure 1. Contd.

in untreated samples (Figures 2 and 3), whereas malaoxon, butanedioic acid, phoratoxon sulfone and ethylmethyl phosphonate were detectable metabolites in the fluids obtained after bacterial growth (Table 1; Figures 4 to 6).
As can be seen from the Table 1 the isolate $P$. aeruginosa yielded the four metabolites while the isolates designated as $P$. aeruginosa MY06 detoxified malathion into ethyl methyl methyl phosphonate. The isolate $P$. aeruginosa SWD also yielded only one metabolite, that 


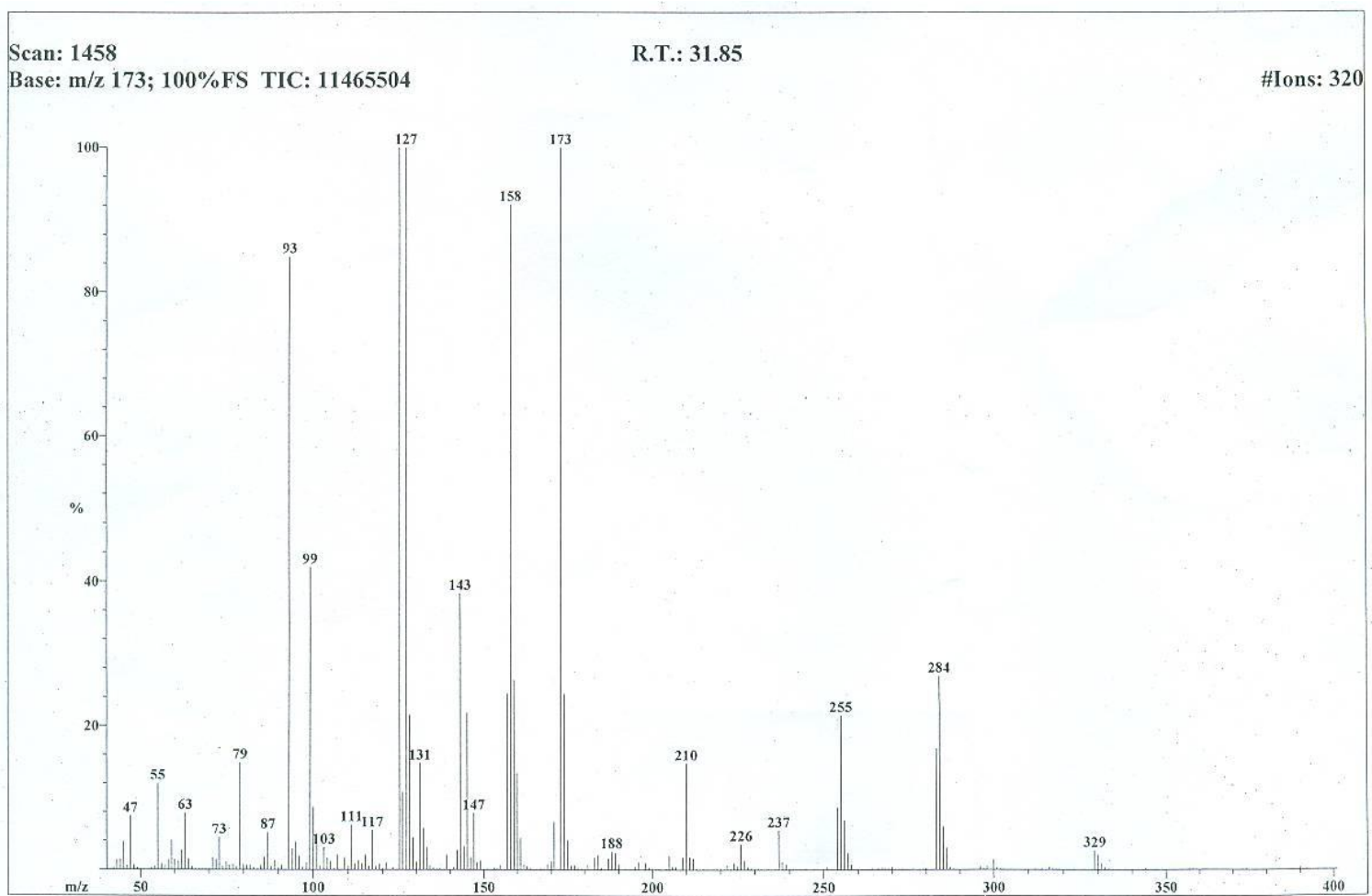

Figure 2. Chromatogram (GC-MS) showing detection of malathion in technical grade used in the study.

$\begin{array}{ll}\text { Scan: } 1309 & \text { R.T.: } 30.43\end{array}$

Base: $\mathrm{m} / \mathrm{z} 173 ; 1.7 \%$ FS TIC: 169248

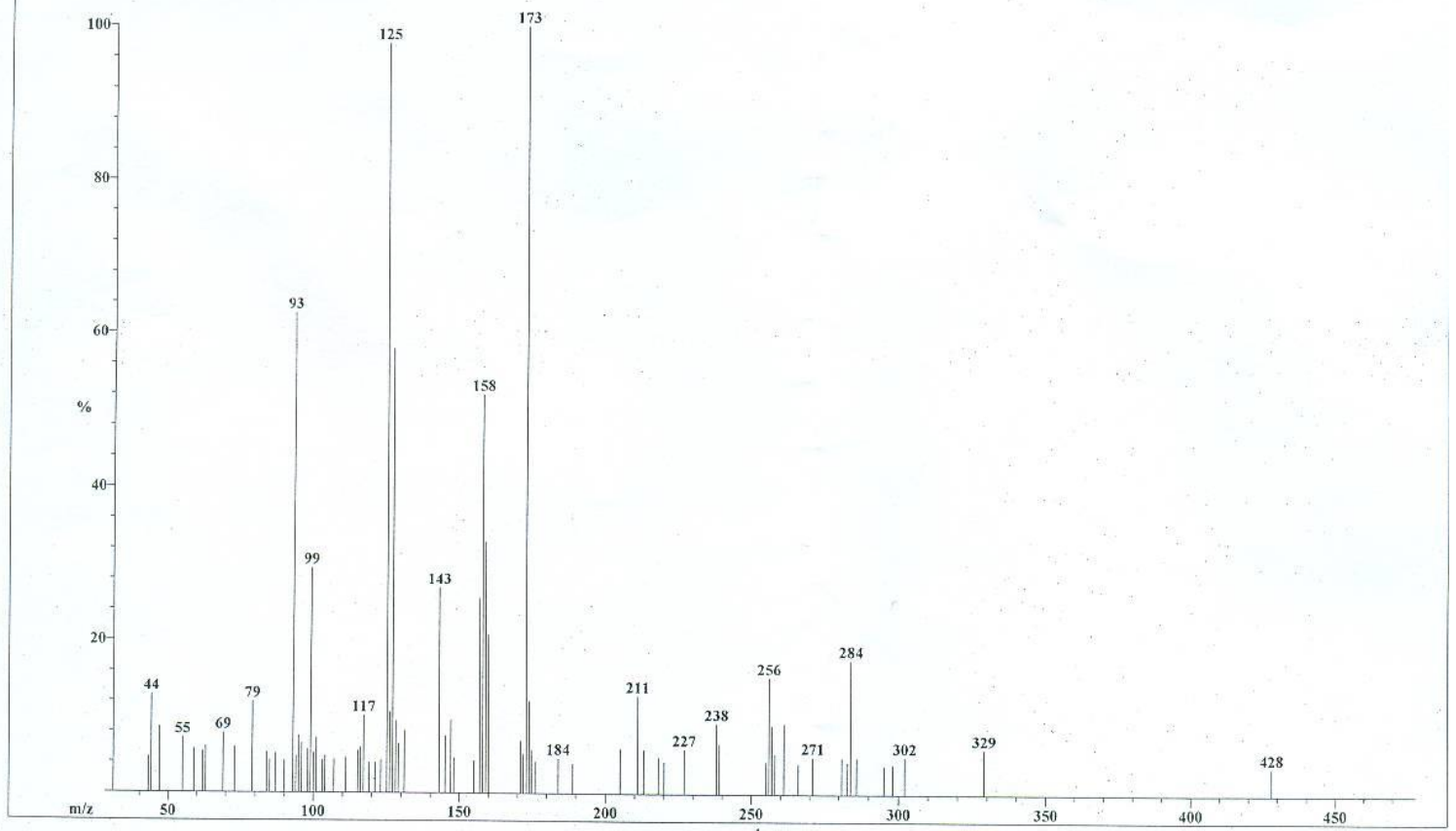

Figure 3. Chromatogram showing GC-MS of $0.5 \%$ malathion un-inoculated (control). 
Table 1. Metabolites produced by bacterial isolates while growing for 7 days in selective medium containing $0.5 \%$ malathion.

\begin{tabular}{|c|c|c|c|c|}
\hline \multirow[b]{2}{*}{ Bacterial Isolate } & \multicolumn{4}{|c|}{ Metabolites } \\
\hline & $\begin{array}{c}\text { Malaoxon } \\
\text { (Mol. wt. 314) }\end{array}$ & $\begin{array}{l}\text { Butanedioic acid } \\
\text { (Mol. wt. 302) }\end{array}$ & $\begin{array}{c}\text { Phoratoxon sulfone } \\
\text { (Mol. wt. 276) }\end{array}$ & $\begin{array}{c}\text { Ethyl methyl methyl- } \\
\text { phosphonate (Mol. wt. 138) }\end{array}$ \\
\hline$P$. aeruginosa & $+v e$ & $+v e$ & $+v e$ & $+v e$ \\
\hline P. aeruginosa MY06 & -ve & $-v e$ & -ve & + ve \\
\hline P. aeruginosa SWD & -ve & + ve & -ve & $-v e$ \\
\hline $\begin{array}{l}\text { Poly-culture of above } \\
\text { three isolates }\end{array}$ & $+\mathrm{ve}$ & -ve & -ve & $+\mathrm{ve}$ \\
\hline
\end{tabular}

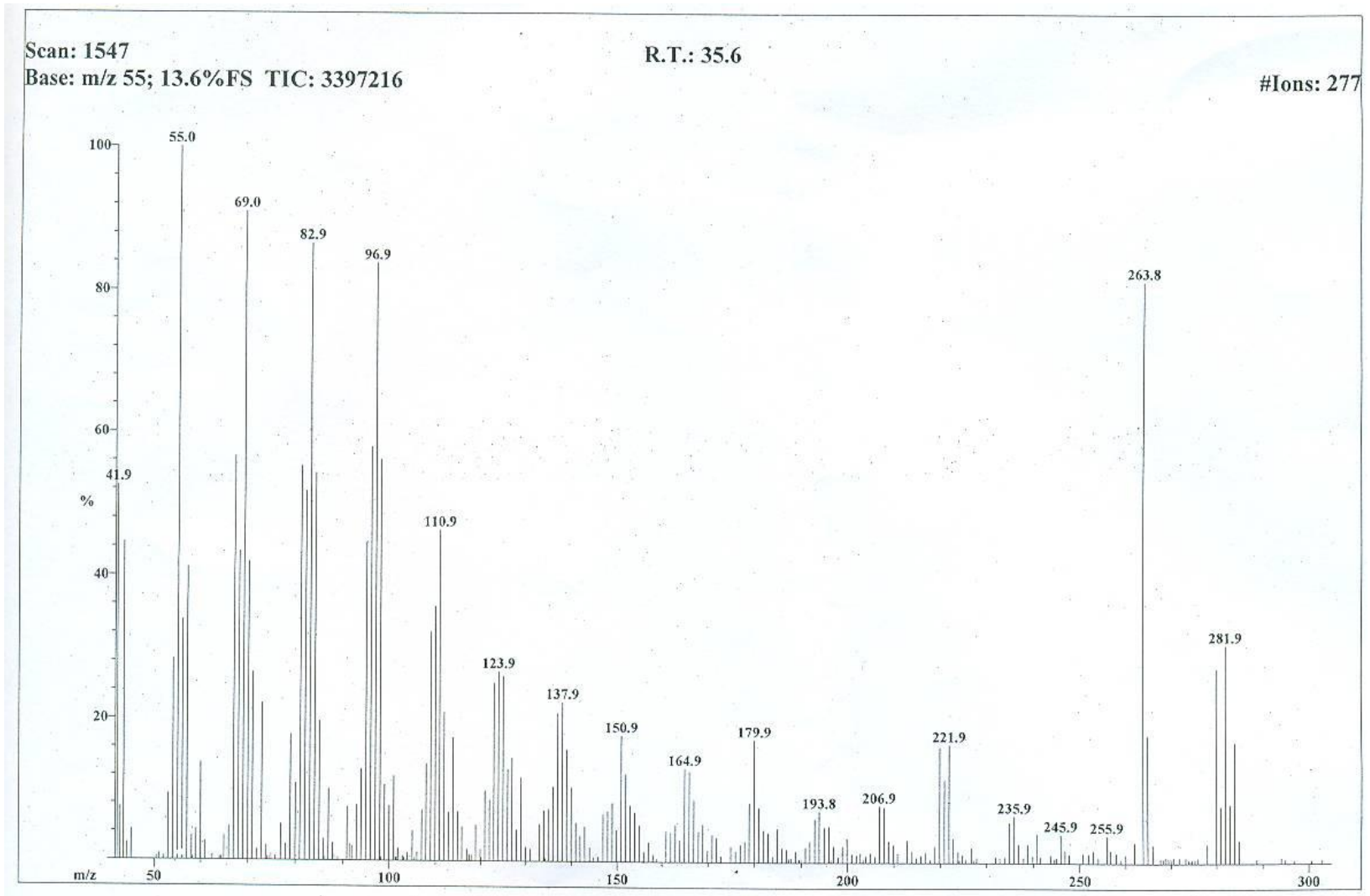

Figure 4. Chromatogram (GC-MS) presenting analysis of a cell-free sample of malathion (concentration $0.5 \%$ ) inoculated with $P$. aeruginosa strain MY06, indicating absence of malathion and presence of ethyl methyl methyl phosphonate.

is, butanedioic acid. Under co-culture conditions (Figure 6 ), only malaoxon and ethyl methyl methyl phosphonate were produced.

\section{DISCUSSION}

In this study, degradation of malathion has been observed by three isolates of Pseudomonas. Various degradation products of malathion, malaoxon, butanedioic acid, phoratoxon sulfone and ethylmethylmethyl phosphonate were detectable. The differential ability of the isolates to yield different sets of the four metabolites reflects their genomic diversity that appeared either in a metabolic scarcity or complete consumption of the non-detectable product by the bacterial isolate. Very interesting observation came from the results of co-culturing experiments, that is, butanedioic acid and phoratoxon sulfone were non-detectable by the analytical techniques employed. This result suggests the change in gene activity of $P$. aeruginosa and $P$. aeruginosa SWD involved in detoxification of malathion. This might had been possible due to 


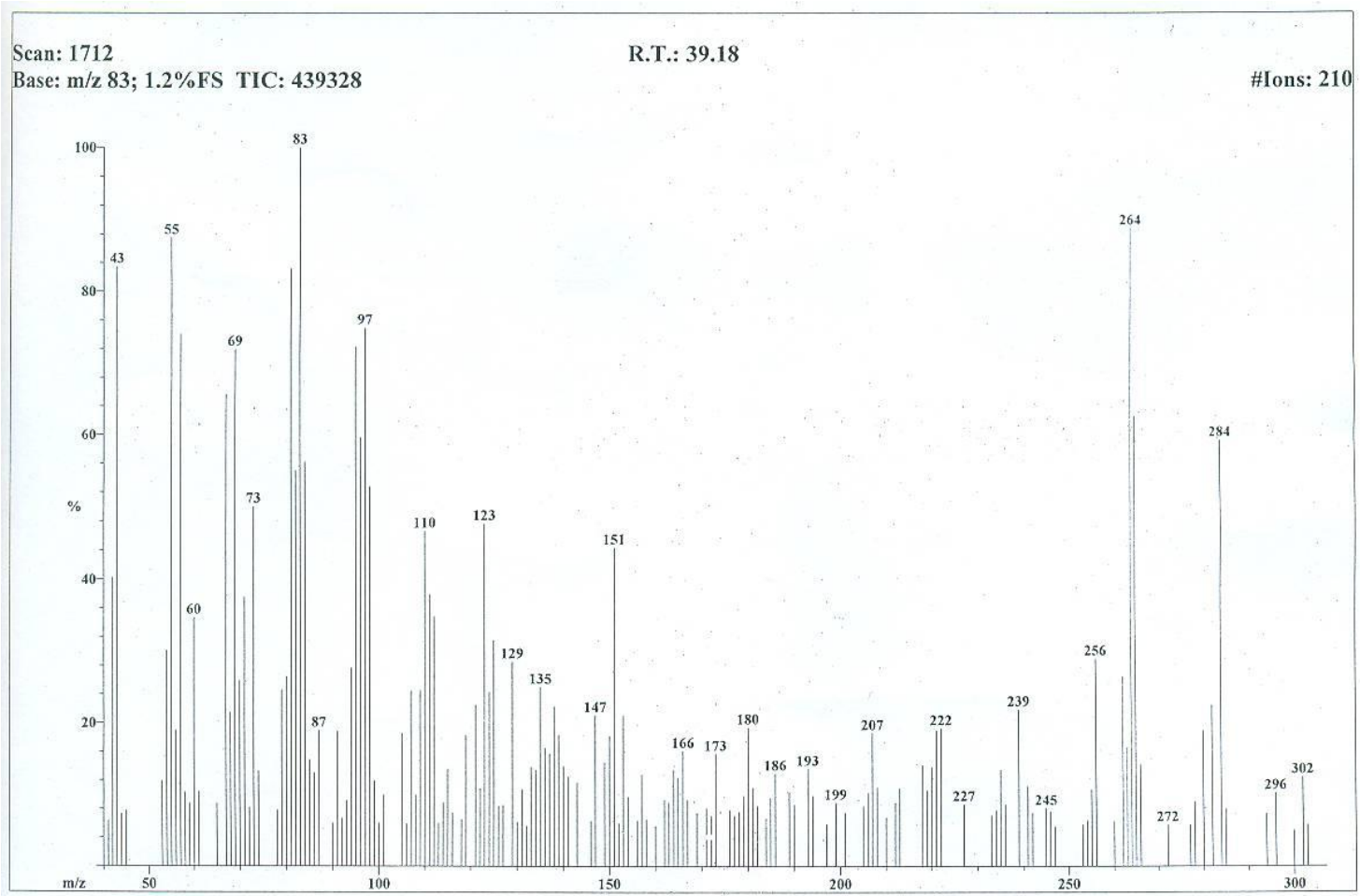

Figure 5. Chromatogram (GC-MS) presenting analysis of cell free sample of malathion (0.5\%) inoculated with $P$. aeruginosa strain SWD indicating absence of malathion and presence of butanedioic acid.

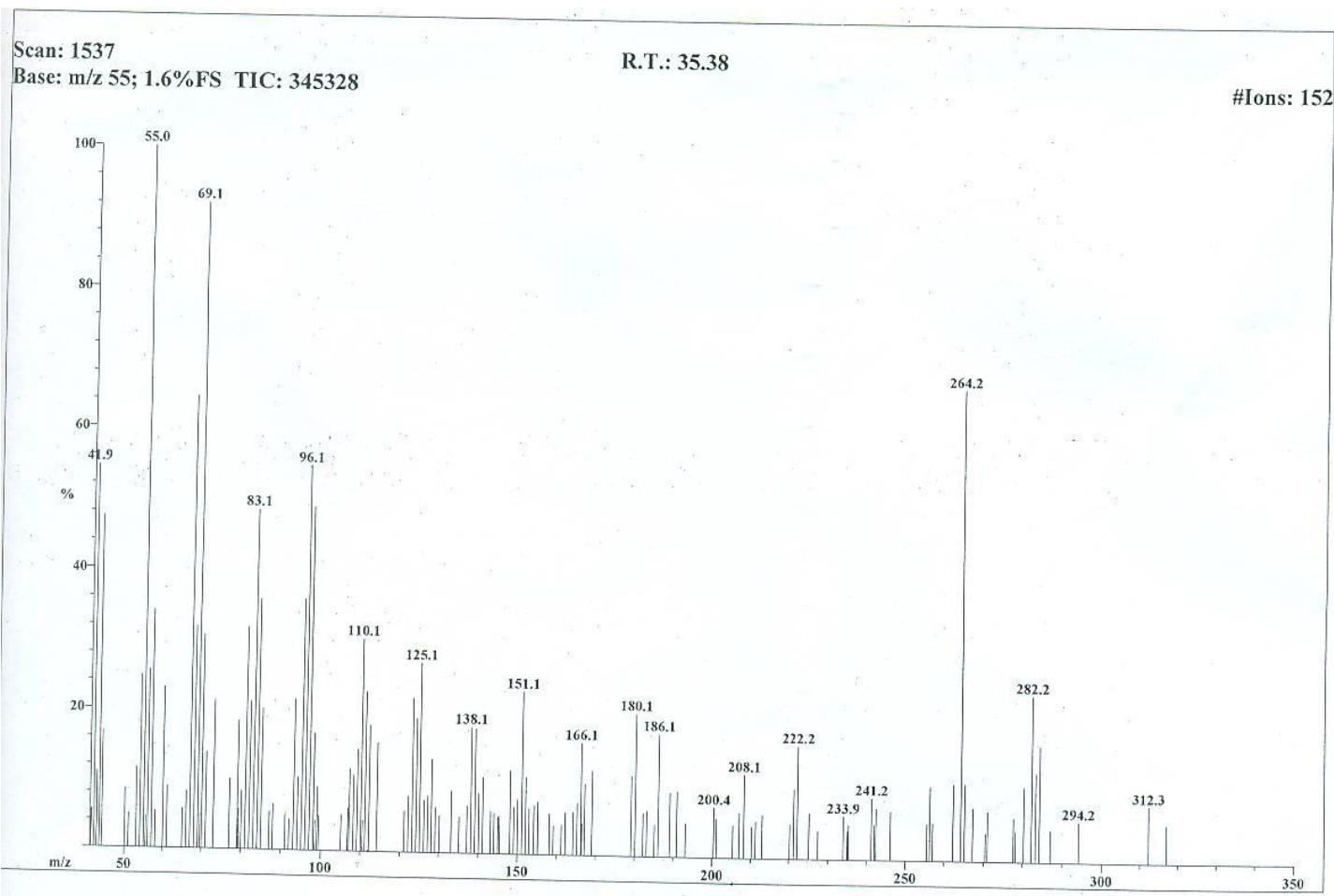

Figure 6. Chromatogram (GC-MS) of cell-free fluid from a co-culture of strains $P$. aeruginosa MY06, $P$. aeruginosa and $P$. aeruginosa SWD. 
accumulative metabolic/enzymatic potentials of the three isolates.

The present results suggest that Pseudomonas has consistent genetic potential that immediately becomes responsive for detoxification of varied nature of pollutants such as detoxification potential of Pseudomonas for naphthalene, nylon oligomer, 4-chlorophenol and toluene, respectively (Guerin and Boyd, 1995; Prijambada et al., 1995; Mclaughlin et al., 2006; Duetz et al., 1996).

Yield of malaoxon by Pseudomonas sp. was paradoxically different from those of Bennett et al. (1984). However, other workers have reported the formation of malathion mono acid (MMA), malathion diacid (MDA) (Talebi and Shibamoto, 2007), malaoxon (Bavcon et al., 2003), diethyl thiosuccinate, O,O-dimethyl phosphorrothionic acid (Pehkonen and Zhang, 2002). Varying reports on the degradation products of malathion are suggestive for considering metabolic differences of the same species' isolates and their biodegradative potential for varying situations.

Numerous studies have suggested mechanism(s) involved in metabolism of malathion by Pseudomonas. Matsumura and Boush (1966) and Singh et al. (1989) isolated Pseudomonas sp. from a contaminated soil, which rapidly degrades malathion through carboxylesteratic hydrolysis as well as desmethylation processes.

Regarding the pathway of biodegradation of malathion, hydrolysis has been found as the most common one (Kim et al., 2005). A number of metabolites of malathion formed in plants, soil and water have been formed as a result of various chemical reactions like de-esterification, oxidation and hydrolysis (Kaur et al., 1997). Presently, the detection of malathion and its degradative metabolites is done routinely and successfully with the advanced techniques like GC/FID (Bavcon et al., 2003) as welll as GC/MS (Talebi and Shibamoto, 2007).

As far as the enzyme for malathion degradation is concerned, dicarboxylesterase has been found responsible both in vivo (Talebi and Shibamoto , 2007) and in vitro (Sun et al., 1992). The enzyme Carboxylesterase (Goda et al., 2010) hydrolase (OP hydrolase) has been isolated from several bacteria but with slower rate (Guha et al., 1997; Horne et al., 2002).

Further work on such lines may yield the identification of bacterial ecological relationship that might prove beneficial in designing biodetoxification model with complete removal of a pollutant with no consequent generation of metabolites that may bear toxicity even greater than the original substrate.

\section{ACKNOWLEDGEMENTS}

The authors are highly grateful to Prof. Dr. Hamid Latif (Late), Institute of Chemistry, University of the Punjab, Lahore for his cooperation as well as HEJ Karachi for providing facility of GC-MS to complete this research work.

\section{REFERENCES}

Andleeb S, Ghauri MA, Qazi JI (2013). Isolation of malathion degrading chromogenic Pseudomonas aeruginosa strains from insecticide impregnated soils. Pak. J. Zool. 45(5):1447-1451.

ATSDR (2008). Medical management guidelines for malathion. Retrieved http://www.atsdr.cdc.gov/substances/toxsubstance. asp?toxid=92.

Bavcon M, Trebse P, Zupancic KL (2003). Investigations of the determination and transformations of diazinon and malathion under environmental conditions using gas chromatography coupled with a flame ionisation detector. Chemosphere, 50:595-601.

Bennett SR, Bane JM, Benford PJ, Pyatt RI (1984). Environmental hazards of chemical agent simulants, CRDC-TR-84055, US Army Chemical Research and Development center, Aberdeen proving ground, MD, (AD B087262L).

Bonner MR, Coble J, Blair A (2007). Malathion exposure and the incidence of cancer in the agricultural health study. Am. J. Epidemiol. 166(9):1023-1034.

Brenner L (1992). Malathion Fact Sheet. J. Pestic. Reform, 12(4).

Delmore JE, Appelhans AD (1991). Detection of agricultural chemical residues on plant leaf surfaces with secondary ion mass spectrometry. Biol. Mass Spectrum, pp. 237-246.

Duetz WA, Marques S, Wind B, Ramos JL, Van Andel JG (1996). Catabolite repression of the toluene degradation pathway in Pseudomonas putida harboring pWW0 under various conditions of nutrient limitation in chemostat culture. Appl. Environ. Microbiol. 62(2):601-606.

Durak D, Uzun FG, Kalender S, Ogutcu A, Uzunhisarcikli M, Kalender Y (2009). Malathion-induced oxidative stress in human erythrocytes and the protective effect of vitamins $\mathrm{C}$ and $\mathrm{E}$ in vitro. Environ. Toxicol. 24:235-242.

Edwards D (2006). Registration eligibility decision for malathion. US Environmental Protection Agency - Prevention, Pesticides and Toxic Substances EPA 738-R-06-030 journal: 9.

Extoxnet (2000). Extension toxicology network pesticide information profiles http://ace.orst.edu/info/extoxnet/pips/malathio.htm.

Goda SK, El Sayed IE, Khodair TA, El Sayed W, Mohamed ME (2010). Screening for and isolation and identification of malathion-degrading bacteria: Cloning and sequencing a gene that potentially encodes the malathion enzyme, carboxylesterase in soil bacteria. Bioremediation, 21(6):903-913.

Guerin WF, Boyd SA (1995). Maintenance and induction of naphthalene degradation activity in Pseudomonas putida and an Alcaligenes sp., under different culture conditions. Appl. Environ. Microbiol. 61(11):4061-4068.

Guha A, Kumari B, Bora TC, Roy MK (1997). Possible involvement of plasmids in degradation of malathion and chlorpyriphos by Micrococcus sp. Folia Microbiol. 42:574-576.

Hamouda SA, Marzouk MA, Abbassy MA, Abd-El-Haleem DA, Shamseldin A (2013). Isolation and identification of efficient Egyptian malathion-degrading bacterial isolates. J. Basic Microbiol. doi: 10.1002/jobm.201300220. [Epub ahead of print].

Horne I, Sutherland TD, Harcourt RL, Russel RJ, Oakeshott JG (2002). Identification of an opd(organophosphate degradation) gene in an Agrobacterium isolate. Appl. Environ. Microbiol. 68:3371-3376.

Howard PH (1991). Handbook of Environmental Fate and Exposure Data of Organic Chemicals. Volume III, Pesticides. Lewis Publishers, CRC Press, Science. 712pp.

Kaur I, Mathur RP, Tandon SN, Dureja P (1997). Identification of metabolites of malathion in plant, water and soil by GC-MS. Biomed. Chromatogr. 11(6):352-355.

Kim YH, AHN Ji Y, Moon SH, Lee J (2005). Biodegradation and detoxification of organophosphate insecticide, malathion by Fusarium oxysporum f. sp. Pisi cutinase. Chemosphere, 60:1349-1355. 
Matsumura F, Boush GM (1966). Malathio degradation by Trichoderma Niride and by a Pseudomonas species. Science, 153(3741):12781280.

Maugh II TH (2010). Study links pesticide to ADHD in children". Los Angeles Times.

Mclaughlin H, Farrell A, Quilty B (2006). Bioaugmentation of activated sludge with two Pseudomonas putida strains for the degradation of 4chlorophenol. J. Environ. Sci. Health 41(5):763-777.

Pehkonen SO, Zhang Q (2002). The degradation of organophosphorus pesticides in natural waters: A critical review. Crit. Rev. Environ. Sci. Technol. 32(1):17-72.

Prijambada ID, Negoro S, Yomo T, Urabe I (1995). Emergence of nylon oligomer degradation enzymes in Pseudomonas aeruginosa PAO through experimental evolution. Appl. Environ. Microbiol. 61(5):20202022.

Shan X, Junxin L, Lin L, Chuanling Q (2009). Biodegradation of malathion by Acinetobacter johnsonii MA 19 and optimization of cometabolism substrates. J. Environ. Sci. 21:76-82.
Singh AK, Srikanth NS, Malhotra OP, Seth PK (1989). Degradation of malathion by microorganisms isolated from industrial effluents. Bull. Environ. Contam. Toxicol. 43:28-35.

Sun CN, Kao CH, Chiang FM (1992). Role of glutathione s-tranferase in organophosphorus resistance of diamondback moth larvae. Proc. $3^{\text {rd }}$ Internat. Conf. PI. Protec. Trop. 3:139-145.

Talebi K, Shibamoto T (2007). Degradation of malathion in aqueous extract obtained from different developmental stages of asparagus (Asparagus officinalis). J. Sc. Food Agri. 87(2):320-325.

US EPA (2013). Malathion for mosquito control. Retrieved from http://www2.epa.gov/mosquitocontrol/malathion 